\title{
Combination of a Lactobacillus-Based Probiotic and Organic Acids Decrease Egg to Chick Weight Loss and Reduce Salmonella spp. Counts in the Litter of Commercial Broiler Breeders
}

\author{
Matias A. Michel' ${ }^{1}$, Fernando A. Revidatti ${ }^{1}$, Ricardo J. Fernández ${ }^{1}$, Martín L. Sindik ${ }^{1}$, Paola Sanz ${ }^{1}$, \\ Xochitl Hernandez-Velasco ${ }^{2}$, Juan D. Latorre ${ }^{3}$, Billy M. Hargis ${ }^{3}$, Guillermo Tellez-Isaias ${ }^{3 *}$ \\ ${ }^{1}$ Facultad de Ciencias Veterinarias, Universidad Nacional del Nordeste, Corrientes, Argentina \\ ${ }^{2}$ Facultad de Medicina Veterinaria y Zootecnia, Universidad Nacional Autonoma de Mexico, Cd. de Mexico, México \\ ${ }^{3}$ Department of Poultry Science, University of Arkansas, Fayetteville, AR, USA \\ Email: ^gtellez@uark.edu
}

How to cite this paper: Michel, M.A., Revidatti, F.A., Fernández, R.J., Sindik, M.L., Sanz, P., Hernandez-Velasco, X., Latorre, J.D., Hargis, B.M. and Tellez-Isaias, G. (2019) Combination of a Lactobacillus-Based Probiotic and Organic Acids Decrease Egg to Chick Weight Loss and Reduce Salmonella spp. Counts in the Litter of Commercial Broiler Breeders. Food and Nutrition Sciences, 10, 1011-1020.

https://doi.org/10.4236/fns.2019.108072

Received: July 29, 2019

Accepted: August 18, 2019

Published: August 21, 2019

Copyright () 2019 by author(s) and Scientific Research Publishing Inc. This work is licensed under the Creative Commons Attribution International License (CC BY 4.0).

http://creativecommons.org/licenses/by/4.0/

\begin{abstract}
The effects of supplementing a blend of organic acids (OA) and a lactic acid bacteria (LAB) based-probiotic on egg to chick weight loss (\%) and Salmonella spp. recovery counts in the litter of commercial broiler breeders were examined in three independent trials during the years 2013, 2014 and 2015. In each trial, ten thousand birds were divided into two groups of 5000 birds (4500 females and 500 males in each group): Control non-treated group, receiving regular water or treated group, receiving $\mathrm{OA}$ and probiotic in the drinking water from 25 to 35 weeks of age. During the ten weeks of evaluation, one thousand fertile eggs or hatched chickens in each trial respectively, were evaluated to obtained, hatching set weight, transferred egg weight, and hatching chick weight, to estimate the difference between egg to chick weight loss (\%). Besides, in trial 2 (2014) and trial 3 (2015), litter samples were collected to evaluate Salmonella spp. counts. The supplementation of OA and probiotic during ten consecutive weeks significantly decreased the egg to chick weight loss (\%) when compared with the control non-treated groups in all three trials evaluated. Interestingly, at the end of the trials 2 and 3, no counts of Salmonella spp. in the litter were detected. In contrast, control-non treated groups resulted in 4.30 and $4.24 \log _{10}$ of Salmonella spp. in trials two and three respectively. The results of the present study suggest that supplementation of OA and a LAB-probiotic for ten consecutive weeks decrease the egg to chick weight loss (\%) and reduce Salmonella spp. counts in the litter of commercial broiler breeders. Higher initial body weight in broiler chickens
\end{abstract}


and reduction of Salmonella spp., clearly justify the use of the combination of these products, as alternatives to antibiotics.

\section{Keywords}

Broiler Breeder, Organic Acid, Probiotic, Salmonella, Litter

\section{Introduction}

Commercial poultry meat production depends on the availability of day-old broiler chickens. Hence, fertility and hatchability are two top parameters correlated with the supply of day-old chicks, and some factors that affect hatchability include genetic line, strain, health, nutrition, the age of the flock, egg quality, egg storage conditions and egg storage duration [1]. Nevertheless, egg weight, eggshell thickness, and porosity are the most influential egg quality parameters that affect hatchability [2]. It has been estimated that two factors influence more than ninety-seven percent of the variation in chick weight at hatch; fresh egg weight and weight loss during incubation. Therefore, the water content on chicken and its yolk sack are directly affected by water loss from hatching eggs during incubation [3]. In commercial hatcheries, eggs lose weight through the loss of water vapor by diffusion across the eggshell. Therefore, weight loss in eggs is always due to water loss, which is determined by the pore geometry of the shell (the gas conductance of the shell) and the humidity in the air around the eggs [4]. For that reason, particular attention must be addressed to adjust the incubator humidity in order to maintain optimum hatchability and chick quality [5] [6].

On the other hand, Foodborne infections by enteropathogens such as Salmonella spp. have significant repercussions on public health and economic losses to the poultry industry. Historically, several methods to control food-borne pathogens have been implemented, including the use of antibiotics. However, there is a great deal of concern that the widespread use of antibiotics will lead to bacterial resistance to those chemicals, and pose a potential risk for public health. Therefore, antibiotics should be limited to infections of specific bacteria with known antibiotic sensitivity, especially when several studies have confirmed that the use of alternatives such as probiotics and organic acids can be an effective tool in controlling salmonellae infections and increase performance of poultry. Recently, we have reported that the supplementation of a blend of organic acids $(\mathrm{OA})$ and a lactic acid bacteria (LAB) based-probiotic significantly reduced the percentage of deformed eggs and weekly-cumulative mortality in commercial broiler breeders [7]. In that study, the increasing numbers of fertile eggs and consequently, broiler chickens at hatch, were positively correlated with a cost-benefit ratio of 1:3.19 suggesting that the combination of $\mathrm{OA}$ and a probiotic may improve production and economic parameters of the breeders [7]. This study intends to present further analysis that was obtained from those three tri- 
als previously published. Hence, the objective of this research report is to evaluate the combination of a LAB-based probiotic and OA on additional production parameters and Salmonella spp. litter counts evaluated and in broiler breeders under commercial conditions.

\section{Materials and Methods}

\subsection{Animals, Housing and Variables Evaluated}

Nine thousand female and one thousand male Cobb 500 breeders were used in each of three independent trials, during three production cycles in the years 2013, 2014 and 2015. All trials were conducted in the same breeder house owned by an integrated commercial poultry company in the Province of Santa Fe, Argentina. Brooding management, maintenance, and production phases, as well as feeding and lighting programs, were conducted according to Cobb Breeder Management Guide [8]. Birds were transferred to the production house at 22 weeks of age. The chicken house had a dimension of $140 \mathrm{~m}$ (459.32 feet) long by $7 \mathrm{~m}$ (22.96 feet) width, providing a density of five breeders per square meter, and it was divided longitudinally into two equal compartments each measuring 140 $\mathrm{m}$ (459.32 feet) by $7 \mathrm{~m}$ (22.96 feet). The division separated experimental groups while having them in the same environmental conditions. The chicken house possessed tunnel ventilation, evaporative panel system and fogging system for cooling which ensure a proper air velocity (maximum $3.5 \mathrm{~m} / \mathrm{seg}$ ). Each section was equipped with automatic feeders and two lines of water with nipples and bell drinkers to administer water treatments. Feeders provided a minimum of 15 $\mathrm{cm}$ of feeding space per female for chain feeders and 12 females per pan to ensure that feed could be distributed in less than 3 minutes. Nipple drinkers were installed at the rate of 6 to 8 birds/nipple. Each section was equipped with communal mechanical nests at a rate of $50 \mathrm{birds} / \mathrm{m}$ of nest floor area, allowing six birds per nest hole in single bird rollaway nests.

During the ten weeks of evaluation of each trial, hatching set weight and transferred egg weight in grams were recorded. Hatching chick weight was also recorded, to estimate the difference between egg to chick weight loss (\%). The temperature and humidity values in eggs storage room for trials 1, 2 and 3 for control and treated groups are shown in Table 1. Temperature and humidity were registered twice a day at $10 \mathrm{AM}$ and $4 \mathrm{PM}$ using a digital Thermo hygrometer with an external sensor which was placed into a wall of eggs storage room. Also, litter samples were collected to evaluate Salmonella spp. counts as described below. All animal handling procedures were in compliance with Institutional Animal Care and Use Committee at the Universidad Nacional del Nordeste, Argentina.

\subsection{Experimental Design}

In each trial, ten thousand broiler breeders were divided into two groups each consisting of 5000 birds (4500 females and 500 males): control group, receiving 
only regular water and treated group, receiving OA in the water at a concentration of $4 \mathrm{~L} / 1000 \mathrm{~L}$ of water according to the manufacturer's directions. Twenty-four hours after OA administration, LAB-probiotic was administered in the drinking water according to the manufacturer's direction. The physical and chemical analysis [9] of the water used in this farm is shown in Table 2. The final concentration delivered once diluted in the drinking water was $10^{6} \mathrm{cfu} / \mathrm{mL}$ of LAB-probiotic.

Table 1. Temperature and humidity average in eggs storage room for control and treated groups.

\begin{tabular}{ccccccc}
\hline \multirow{2}{*}{$\begin{array}{c}\text { Broiler breeders } \\
\text { age (weeks) }\end{array}$} & \begin{tabular}{c} 
Trial 1 (2013) \\
\cline { 2 - 6 }$\left({ }^{\circ} \mathrm{C}\right)$
\end{tabular} & $\begin{array}{c}\text { Tumidity } \\
(\%)\end{array}$ & $\begin{array}{c}\text { Temperature } \\
\left({ }^{\circ} \mathrm{C}\right)\end{array}$ & $\begin{array}{c}\text { Humidity } \\
(\%)\end{array}$ & $\begin{array}{c}\text { Temperature } \\
\left({ }^{\circ} \mathrm{C}\right)\end{array}$ & $\begin{array}{c}\text { Humidity } \\
(\%)\end{array}$ \\
\hline 25 & 22.1 & 55 & 23.0 & 47 & 22.2 & 51 \\
26 & 23.3 & 49 & 23.1 & 61 & 23.6 & 46 \\
27 & 21.6 & 40 & 23.2 & 53 & 23.5 & 49 \\
28 & 22.7 & 35 & 22.9 & 60 & 23.0 & 43 \\
29 & 21.9 & 33 & 23.1 & 44 & 23.2 & 47 \\
30 & 21.7 & 49 & 22.8 & 39 & 23.1 & 43 \\
31 & 23.1 & 60 & 21.9 & 69 & 23.0 & 63 \\
32 & 22.7 & 48 & 22.5 & 67 & 22.7 & 50 \\
33 & 23.1 & 61 & 21.5 & 49 & 22.8 & 53 \\
34 & 22.6 & 58 & 22.2 & 56 & 22.4 & 40 \\
35 & 22.8 & 60 & 24.1 & 44 & 23.2 & 55 \\
\hline
\end{tabular}

Table 2. Physical and chemical analysis of the water used in the farm where all trials were conducted.

\begin{tabular}{ccc}
\hline & Units & Results \\
\hline $\mathrm{pH}$ & $\mathrm{mg} / \mathrm{L}$ & 7.95 \\
Fixed components (thermic dried, $130^{\circ} \mathrm{C}$ ) & $\mathrm{mg} / \mathrm{L}$ & 367.00 \\
Volatile components (qualitative organic content) & $\mathrm{mg} / \mathrm{L}$ & 64.00 \\
Organic content & $\mathrm{mgO} / \mathrm{L}$ & ---- \\
Suspended solid (filter $0.45 \mu \mathrm{m})$ & $\mathrm{mg} / \mathrm{L}$ & ---- \\
Total salinity $\left(105^{\circ} \mathrm{C}\right)$ & $\mathrm{mg} / \mathrm{L}$ & 431.00 \\
Total hardness & $\mathrm{mg} / \mathrm{L} \mathrm{CaCO}{ }_{3}$ & 623.48 \\
Calcium hardness & $\mathrm{mg} \mathrm{Ca} / \mathrm{L}$ & 174.10 \\
Magnesium hardness & $\mathrm{mg} / \mathrm{L}$ & 45.51 \\
Sulfates & $\mathrm{mg} / \mathrm{L}$ & 250.00 \\
Chlorides & $\mathrm{mg} / \mathrm{L}$ & 21.85 \\
Total nitrogen & $\mathrm{mg} / \mathrm{L}$ & 0.28 \\
Nitrates & $\mathrm{mg} / \mathrm{L}$ & 0.239 \\
Iron & $\mathrm{mg} / \mathrm{L}$ & $-\cdots--$ \\
\hline
\end{tabular}

All procedures were made according to AOAC International (2012). 
These treatments were administrated once per week during the trials. For all trials, OA was administered on Monday for 8 hours. On Tuesday, LAB-probiotic was administered for 6 hours. These treatments were administered every week for ten consecutive weeks, starting from week 25 to week 35 of age. This period was selected because it is when egg production starts and reaches the peak of production, representing a period of high physiological demand for the hen. Wednesday was the day to collect hatching set weight, transferred egg weight, and hatching chick weight respectively in all three trials. Hence, in each trial, every week for ten weeks, one thousand eggs or chickens were weighted respectively.

\subsection{Probiotic Culture}

The probiotic used in these trials is a defined lactic acid base probiotic culture (FloraMax ${ }^{\circledR}$ B11). This product was administered according to the manufacturer's instructions (Pacific Vet Group USA Inc., Fayetteville, AR, USA).

\subsection{Organic Acids}

This commercial OA product (Optimizer ${ }^{\mathrm{rm}}$ ) is a combination of five different OA (lactic, acetic, tannic, propionic, and caprylic acids) that contains proprietary flavoring agents. This product was administered according to the manufacturer's instructions (Pacific Vet Group USA Inc., Fayetteville, AR, USA).

\subsection{Bacteriologic Evaluation of the Litter}

Bacteriologic evaluation of the litter was performed only in trials 2 (2014) and 3 (2015). Litter was evaluated before and after ten consecutive weeks of treatment. Breeder houses in the control and test groups were divided into three sectors near the feeder and drinking lines along the house. In each sector, ten samples of litter, each consisting of $25 \mathrm{~g}$, were collected into sterile bags $(\mathrm{n}=30 / \mathrm{house})$. Samples were weighed and 1:4 wt/vol dilutions were made with sterile $0.9 \%$ saline. Ten-fold dilutions of each sample, from each group were made in a sterile 96 well Bacti flat bottom plate, and the diluted samples were plated on Xylose-Lysine-Desoxycholate Agar (Becton Dickinson, Heidelberg, Germany) to evaluate the total number of Salmonella spp.

\subsection{Statistical Analysis}

Hatching set weight, transferred egg weight, hatching chick weight and the difference between egg to chicken weight loss data, as well as $\log _{10}$ cfu/g of Salmonella spp. counts data were subjected to one-way analysis of variance as a completely randomized design, using the General Linear Models procedure in SAS [10]. Significant differences among the means were determined by Duncan's multiple range test at $\mathrm{P}<0.05$.

\section{Results and Discussion}

The results of the parameters evaluated in broiler breeders with or without sup- 
plementation of OA and a LAB-probiotic are summarized in Table 3. No significant differences were observed on eggs set weight, transferred egg weight, one-day chick weight or egg to chick weight difference in any of the trials between control and treated birds $(\mathrm{P}>0.05)$. However, supplementation of OA and probiotic during ten consecutive weeks significantly decreased the egg to chick weight loss (\%) when compared with the control non-treated groups in all three trials (Table 3). Since modern broiler chickens are generally raised for 39 to 56 days, the twenty-one days of incubation plus the first seven days post-hatch nutrition, in reality, represent $36 \%$ to $47 \%$ of the production life of a broiler chicken. Therefore, using programs that increase the performance of breeders and their progeny may have a positive impact to enhance their health and welfare.

On the other hand, the body weight of broiler chicks at hatch is predominantly determined by initial egg weight, representing $62 \%-78 \%$ of the egg weight [2]. However, day-old chick weight is also influenced by weight loss during incubation, eggshell weight, residue weight, breeder' strain, as well as the age of the breeders [5]. It has been estimated that $1 \mathrm{~g}$ change in egg weight results in a corresponding change of $2-13 \mathrm{~g}$ in broiler weight at 6 to 8 weeks of age, and this effect is highly correlated with the age of the breeders [11]. Scientific reports have revealed that dietary inclusion of probiotics used as direct-fed microbial (DFM) increase eggshell quality, egg production, egg weight, egg mass and eggshell thickness [12]. Utilization of DFM has also shown to improve gut microflora balance, clearly demonstrating the importance of keeping the integrity of the gastrointestinal tract by manipulating the gut microbiome positively and improving egg production and eggshell quality [13] [14]. Some of the mechanisms associated with the improvement of eggshell quality by nutraceuticals include the increasing rate of fermentation [15]. Organic acids and short chain fatty acids have a substantial effect in digestive physiology such as reduction of luminal $\mathrm{pH}$, increased calcium absorption, and angiogenesis, as well as stimulation of intestinal epithelial cell proliferation [16]. Manipulation of beneficial bacteria in the gut has been reported to improve the metabolism of the host animals in

Table 3. Parameters evaluated in broiler breeders with or without supplementation of organic acids (OA) and a lactic acid bacteria-based probiotic. Treatments were applied weekly by drinking water $\left(\mathrm{OA}=4: 1 \mathrm{~L}\right.$; Probiotics $\left.=10^{6} \mathrm{cfu} / \mathrm{mL}\right)$; data were collected during ten consecutive weeks (25 - 35 weeks).

\begin{tabular}{ccccccc}
\hline \multirow{2}{*}{ Performance parameter } & \multicolumn{2}{c}{ Trial 1 (2013) } & \multicolumn{2}{c}{ Trial 2 (2014) } & \multicolumn{2}{c}{ Trial 3 (2015) } \\
\cline { 2 - 7 } & Control & OA + Probiotic & Control & OA + Probiotic & Control & OA + Probiotic \\
\hline Eggs set weight $(\mathrm{g})$ & $61.2 \pm 0.61$ & $60.38 \pm 0.49$ & $59.63 \pm 0.90$ & $59.84 \pm 0.85$ & $58.29 \pm 0.77$ & $58.19 \pm 0.78$ \\
Transferred egg weight $(\mathrm{g})$ & $57.47 \pm 0.47$ & $57.91 \pm 0.41$ & $56.73 \pm 0.72$ & $57.18 \pm 0.67$ & $54.1 \pm 0.73$ & $54.13 \pm 0.72$ \\
One-day chick weight (g) & $45.04 \pm 0.47$ & $44.81 \pm 0.42$ & $44.18 \pm 0.46$ & $44.61 \pm 0.50$ & $42.35 \pm 0.49$ & $42.49 \pm 0.63$ \\
Egg to chick weight difference (g) & $16.16 \pm 0.09$ & $15.57 \pm 0.09$ & $15.45 \pm 0.09$ & $15.23 \pm 0.09$ & $15.93 \pm 0.09$ & $15.7 \pm 0.09$ \\
Egg to chick weight loss (\%) & $26.41 \pm 0.06$ & $25.79 \pm 0.06^{*}$ & $25.91 \pm 0.06$ & $25.45 \pm 0.06^{*}$ & $27.34 \pm 0.06$ & $26.99 \pm 0.06^{*}$ \\
\hline
\end{tabular}

Data expressed as mean \pm SE. Every week for ten weeks, 1000 eggs or chickens were weighted respectively. ${ }^{*}$ Mean values significantly differ between experimental treatments $(\mathrm{P}<0.05)$. 
various ways, including absorptive capacity, protein metabolism, energy metabolism, fiber digestion, and gut maturation [17] [18]. Balanced gastrointestinal microbiota and immune-stimulation are significant functional effects attributed to the consumption of probiotics [17] [19]. Likewise, nutritional components of the diet are also of critical importance not only for meeting the nutrient requirements of the breeders but also for their gastrointestinal microflora [20].

Table 4 shows the results of the Salmonella spp. counts in the litter of broiler breeders with or without supplementation of OA and a LAB-probiotic in trials 2 (2014) and 3 (2015). In both trials, control and treated groups have no counts of Salmonella spp. in the litter. However, 10 weeks after OA and probiotic supplementation, it was remarkable to observe that supplementation of OA and probiotics for 10 consecutive weeks kept the same level of non-detection of Salmonella spp., meanwhile control non-treated litter had an increase of 4.30 and 4.24 $\log _{10}$ of Salmonella spp. in trials 2 and 3 respectively (Table 4). These results are noteworthy, considering that the company does not apply any treatment or litter amendment used to control.

Furthermore, the significant reduction on environmental Salmonella spp. are in agreement with previous results conducted by our laboratory where the combination of the OA and probiotic used in this study reduced the prevalence of Salmonella spp. in the litter of commercial turkey houses [21]. In this regard, our laboratory has published reports showing that the defined lactic acid bacteria-based probiotic culture (FloraMax ${ }^{\circledR}$ B11) improves the development of healthy microflora in chickens and turkeys, providing increased resistance to Salmonella spp. infections in both laboratory and commercial trials [20]. Also, previous research from our laboratory indicates a very rapid induction of specific host-gene expression pathways, which are associated with reductions in enteric colonization with Salmonella [21]. While many mechanisms of action have been proposed for the observed efficacy, precise modalities have not been wholly described for this highly effective culture.

On the other hand, in recent years OA based feed acidifiers have gained acceptance in the poultry industry due to their high nutritional value and antimicrobial

Table 4. Salmonella spp. counts in the litter of broiler breeders with or without supplementation of organic acids and a LAB-probiotic in trials 2 and 3. Treatment was applied weekly by drinking water $\left(\mathrm{OA}=4: 1 \mathrm{~L}\right.$; Probiotics $\left.=10^{6} \mathrm{cfu} / \mathrm{mL}\right)$; litter samples were collected a day before and after every trial ( 25 and 35 weeks).

\begin{tabular}{|c|c|c|c|c|}
\hline \multirow{2}{*}{ Group } & \multicolumn{2}{|c|}{ Trial 2 (2014) } & \multicolumn{2}{|c|}{ Trial 3 (2015) } \\
\hline & Pre-treatment & Post-treatment & Pre-treatment & Post-treatment \\
\hline Control & $0.00 \pm 0.00^{\mathrm{a}, \mathrm{y}}$ & $4.30 \pm 0.30^{\mathrm{a}, \mathrm{x}}$ & $0.00 \pm 0.00^{\mathrm{a}, \mathrm{y}}$ & $4.24 \pm 0.24^{\mathrm{a}, \mathrm{x}}$ \\
\hline $\mathrm{OA}+$ Probiotic & $0.00 \pm 0.00^{\mathrm{a}, \mathrm{y}}$ & $0.00 \pm 0.00^{\mathrm{b}, \mathrm{y}}$ & $0.00 \pm 0.00^{\mathrm{a}, \mathrm{y}}$ & $0.00 \pm 0.00^{\mathrm{b}, \mathrm{y}}$ \\
\hline
\end{tabular}

Data expressed as $\log _{10}$ of $\mathrm{cfu} / \mathrm{g}$ of litter $\pm \mathrm{SE}$; Breeder houses in the control and test groups were divided into three sectors near the feeder and drinking lines along the house. In each sector, ten samples of litter (25 g) were collected into sterile bags $\left(\mathrm{n}=30\right.$ /house). ${ }^{\mathrm{a}, \mathrm{b}}$ Superscripts within columns indicate significant difference among sample source $(P<0.05) .{ }^{x, y}$ Superscripts within rows indicate significant difference among sample source $(\mathrm{P}<0.05)$. 
benefits [16] [22]. Previously, we have showed that a commercially available water treatment product $\left(\right.$ Optimizer $\left.^{\mathrm{rm}}\right)$ ) significantly increase water consumption and cellular water retention, hence reducing carcass condemnation at the processing plant, mortality during transportation, and body weight loss, suggesting that this organic acid product may improve animal welfare and economic concerns in the poultry industry [23]. Additionally, OA also has shown to have a profound impact on the intestinal microbiome [24]. In summary, the results of the present study suggest that supplementation of $\mathrm{OA}$ and a LAB-probiotic for ten consecutive weeks (from week 25 to 35) decrease the egg to chick weight loss and reduce Salmonella spp. counts in the litter of commercial broiler breeders. Further studies to evaluate the effect of the supplementation of OA and LAB-probiotic for ten consecutive weeks on the physical and chemical composition of the eggshell as well as electron microscopy are currently being evaluated. Besides, litter moisture content and $\mathrm{pH}$ of the litter samples will also be determined.

\section{Conflicts of Interest}

The authors declare no conflicts of interest regarding the publication of this paper.

\section{References}

[1] King'Ori, A. (2011) Review of the Factors that Influence Egg Fertility and Hatchability in Poultry. International Journal of Poultry Science, 10, 483-492. https://doi.org/10.3923/ijps.2011.483.492

[2] Wilson, H. (1991) Interrelationships of Egg Size, Chick Size, Post-Hatching Growth, and Hatchability. World s Poultry Science Journal, 47, 5-20. https://doi.org/10.1079/WPS19910002

[3] Tullett, S.G. and Burton, F.G. (1982) Factors Affecting the Weight and Water Status of the Chick at Hatch. British Poultry Science, 23, 361-369. https://doi.org/10.1080/00071688208447969

[4] Deeming, C.D. (2011) A Review of the Relationship between Eggshell Colour and Water Vapour Conductance. Avian Biology Research, 4, 224-230. https://doi.org/10.3184/175815511X13207819436147

[5] Peebles, E., Brake, J. and Gildersleeve, R. (1987) Effects of Eggshell Cuticle Removal and Incubation Humidity on Embryonic Development and Hatchability of Broilers. Poultry Science, 66, 834-840. https://doi.org/10.3382/ps.0660834

[6] Renema, R., Robinson, F. and Zuidhof, M. (2007) Reproductive Efficiency and Metabolism of Female Broiler Breeders as Affected by Genotype, Feed Allocation, and Age at Photostimulation. 2. Sexual Maturation. Poultry Science, 86, 2267-2277. https://doi.org/10.1093/ps/86.10.2267

[7] Michel, M.A., Revidatti, F.A., Fernández, R.J., Sindik, M.L., Sanz, P., Hernandez-Velasco, X., Latorre, J.D., Hargis, B.M. and Tellez, G. (2017) Evaluation of a Commercially Available Probiotic and Organic Acid Blend Product on Production Parameters and Economics in Broiler Breeders. Nutrition and Food Technology, 3, 1-5. https://doi.org/10.16966/2470-6086.139

[8] Cobb-Vantress Inc (2013) Breeder Management Supplement Cobb500. https://www.academia.edu/36952731/Breeder_Management_Supplement_Co bb_500_SF_Breeder_Management_Supplement 
[9] AOAC International (2012) Official Methods of Analysis of AOAC International. 19th Edition, AOAC Int., Gaithersburg, MD.

[10] SAS Institute (2002) SAS User Guide. Version 9.1, SAS Inst. Inc., Cary, NC.

[11] Bergoug, H., Burel, C., Guinebretiere, M., Tong, Q., Roulston, N., Romanini, C.E.B., Exadaktylos, V., McGonnell, I.M., Demmers, T.G.M., Verhelst, R., Bahr, C., Berckmans, D. and Eterradossi, N. (2013) Effect of Pre-Incubation and Incubation Conditions on Hatchability, Hatch Time and Hatch Window, and Effect of Post-Hatch Handling on Chick Quality at Placement. World's Poultry Science Journal, 69, 313-334. https://doi.org/10.1017/S0043933913000329

[12] Abdel-Wareth, A.A. (2016) Effect of Dietary Supplementation of Thymol, Synbiotic and Their Combination on Performance, Egg Quality and Serum Metabolic Profile of Hy-Line Brown Hens. British Poultry Science, 57, 114-122. https://doi.org/10.1080/00071668.2015.1123219

[13] Abdelqader, A., Irshaid, R. and Al-Fataftah, A.R. (2013) Effects of Dietary Probiotic Inclusion on Performance, Eggshell Quality, Cecal Microflora Composition, and Tibia Traits of Laying Hens in the Late Phase of Production. Tropical Animal Health and Production, 45, 1017-1024. https://doi.org/10.1007/s11250-012-0326-7

[14] Sobczak, A. and Kozłowski, K. (2015) The Effect of a Probiotic Preparation Containing Bacillus subtilis ATCC PTA-6737 on Egg Production and Physiological Parameters of Laying Hens. Annals of Animal Science, 15, 711-723.

https://doi.org/10.1515/aoas-2015-0040

[15] Tellez, G., Higgins, S.E., Donoghue, A.M. and Hargis, B.M. (2006) Digestive Physiology and the Role of Microorganisms. The Journal of Applied Poultry Research, 15, 136-144. https://doi.org/10.1093/japr/15.1.136

[16] Ricke, S. (2003) Perspectives on the Use of Organic Acids and Short Chain Fatty Acids as Antimicrobials. Poultry Science, 82, 632-639. https://doi.org/10.1093/ps/82.4.632

[17] Borchers, A.T., Selmi, C., Meyers, F.J., Keen, C.L. and Gershwin, M.E. (2009) Probiotics and Immunity. Journal of Gastroenterology, 44, 26-46. https://doi.org/10.1007/s00535-008-2296-0

[18] Bäckhed, F. (2011) Programming of Host Metabolism by the Gut Microbiota. Annals of Nutrition \& Metabolism, 58, 44-52. https://doi.org/10.1159/000328042

[19] Maslowski, K.M. and Mackay, C.R. (2010) Diet, Gut Microbiota and Immune Responses. Nature Immunology, 12, 5-9. https://doi.org/10.1038/ni0111-5

[20] Tellez, G., Pixley, C., Wolfenden, R., Layton, S.L. and Hargis, B.M. (2012) Probiotics/Direct Fed Microbials for Salmonella Control in Poultry. Food Research International, 45, 628-633. https://doi.org/10.1016/j.foodres.2011.03.047

[21] Higgins, S.E., Wolfenden, A.D., Tellez, G., Hargis, B.M. and Porter, T.E. (2011) Transcriptional Profiling of Cecal Gene Expression in Probiotic-and Salmonella-Challenged Neonatal Chicks. Poultry Science, 90, 901-913. https://doi.org/10.3382/ps.2010-00907

[22] Vicente, J., Higgins, S., Bielke, L., Tellez, G., Donoghue, D., Donoghue, A. and Hargis, B. (2007) Effect of Probiotic Culture Candidates on Salmonella Prevalence in Commercial Turkey Houses. The Journal of Applied Poultry Research, 16, 471-476. https://doi.org/10.1093/japr/16.3.471

[23] Menconi, A., Kuttappan, V., Hernandez-Velasco, X., Urbano, T., Matté, F., Layton, S., Kallapura, G., Latorre, J., Morales, B., Prado, O., Vicente, J.L., Barton, J., Andreatti Filho, R.L., Lovato, M., Hargis, B.M. and Tellez, G. (2014) Evaluation of a 
Commercially Available Organic Acid Product on Body Weight Loss, Carcass Yield, and Meat Quality during Preslaughter Feed Withdrawal in Broiler Chickens: A Poultry Welfare and Economic Perspective. Poultry Science, 93, 448-455.

https://doi.org/10.3382/ps.2013-03444

[24] Oakley, B.B., Buhr, R.J., Ritz, C.W., Kiepper, B.H., Berrang, M.E., Seal, B.S. and Cox, N.A. (2014) Successional Changes in the Chicken Cecal Microbiome during 42 Days of Growth Are Independent of Organic Acid Feed Additives. BMC Veterinary Research, 10, 282. https://doi.org/10.1186/s12917-014-0282-8 